\title{
Depletion and repletion of fruit and vegetable intake alters serum bone turnover markers: a 28-week single-arm experimental feeding intervention
}

\author{
Jay J. CaO ${ }^{1 *}$, Leah D. Whigham ${ }^{1,2}$ and Lisa Jahns ${ }^{1 *}$ \\ ${ }^{1}$ US Department of Agriculture, Agricultural Research Service, Grand Forks Human Nutrition Research Center, Grand Forks, \\ ND 58202, USA \\ ${ }^{2}$ Paso del Norte Institute for Healthy Living, El Paso, TX 79901, USA
}

(Submitted 13 October 2017 - Final revision received 18 May 2018 - Accepted 29 May 2018 - First published online 19 July 2018)

\section{Abstract}

This study was designed to evaluate the effects of elevated fruit and vegetable intake on bone turnover markers. In all, twenty-nine subjects (nine male and twenty female, with a mean age of 32.1 (sем 2.5) years) participated in a 28 -week single-arm experimental feeding intervention trial and consumed a prescribed low-fruit and vegetable diet for 6 weeks (depletion-1), a provided high-fruit and vegetable diet for 8 weeks (fruit: 360-560 g; vegetables: 450-705 g), another prescribed low-fruit and vegetable diet for 6 weeks (depletion-2) and then their usual diets for 8 weeks (repletion). Serum bone-related biomarkers were analysed with commercial ELISA kits. Plasma carotenoid levels decreased as a result of the depletion phase and increased with the high-fruit and vegetable diet. Compared with the baseline, depletion-1 resulted in higher serum bone resorption marker C-terminal telopeptide of type 1 collagen (CTX) and lower bone formation marker alkaline phosphatase (BAP)

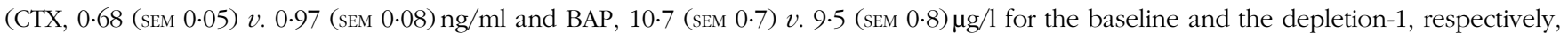
$P<0.05$ ). High intake of fruit and vegetables decreased serum CTX $(P<0.05)$ to 0.60 (SEM 0.04$) \mathrm{ng} / \mathrm{ml}$ and increased serum BAP to 11.3 (SEM 0.7) $\mu \mathrm{g} / \mathrm{l}(P<0.05)$, compared with the depletion-1 phase. Serum concentrations of CTX were inversely correlated and those of BAP were positively correlated with blood lycopene. These data show that increased fruit and vegetable consumption at or above federal dietary guidance may be beneficial to bone health.

\section{Key words: Fruits: Vegetables: Bone: Resorption: Formation: Acid-base balance: Carotenoids}

Dietary and lifestyle modifications have an important role in the prevention of many chronic diseases. Fruit and vegetables, rich in many nutrients and non-nutritive biologically active constituents, are generally considered an essential part of a healthy diet ${ }^{(1)}$. The 2015 Dietary Guidelines for Americans recommend a daily intake of fruit and vegetables of at least five servings (about $1050 \mathrm{~g}$ ) per $\mathrm{d}^{(1)}$. Convincing evidence consistently supports that diets high in fruit and vegetables are associated with reduced risk of many chronic diseases such as $\mathrm{CVD}^{(2,3)}$, type 2 diabetes $^{(4)}$ and some cancers ${ }^{(5,6)}$. Furthermore, evidence supports that increased consumption of fruit and vegetables may reduce overweight or obesity ${ }^{(7)}$ and prolong life $\mathrm{e}^{(3,8)}$.

The beneficial effects of fruit and vegetables on chronic diseases are thought to be through reducing oxidative stress and inflammation processes or diet-induced metabolic acidosis ${ }^{(9)}$, all of which influence bone health. Fruit and vegetables contain vitamins, minerals and other phytochemicals that are beneficial to bone $^{(10)}$. Indeed, several cross-sectional and longitudinal studies demonstrate that elevated fruit and vegetable intake is associated with increased bone mass ${ }^{(11-13)}$ and lower risk of bone fracture ${ }^{(9,14)}$. Contrary to the above findings, Feart et al. ${ }^{(15)}$ found that adherence to a Mediterranean diet rich in fruit and vegetables was not associated with lower risk of fracture, and Hamidi et al. ${ }^{(10)}$ also found no clear benefits of fruit and vegetable intake on bone health for women aged 45 years or older.

Data from controlled intervention trials are lacking that support or refute observational evidence, suggesting a positive association between intake of fruit and vegetables and bone health. Moreover, there are scant clinical data providing insight into the mechanisms through which fruit and vegetables affect bone. Therefore, in the current study, we aimed to determine whether depletion and repletion intake of fruit and vegetables influence serum markers of bone turnover. We hypothesised that elevated fruit and vegetable intake improves serum markers of bone turnover. To test this hypothesis, we analysed bone biomarkers as secondary end points in serum samples collected from a 28-week single-arm experimental feeding

Abbreviations: BAP, bone-specific alkaline phosphatase; CTX, C-terminal telopeptide of type 1 collage; IGF-1, insulin-like growth factor 1; PRAL, potential renal acid load.

* Corresponding authors: J. J. Cao, fax +1 701795 8220, email Jay.Cao@ars.usda.gov; L. Jahns, email Lisa.Jahns@ars.usda.gov 
intervention in which fruit and vegetable intake was increased for 8 weeks in a controlled feeding intervention.

\section{Methods}

\section{Subjects and experimental design}

The study used a 28-week single-arm, experimental feeding intervention design and was part of a larger trial designed to assess changes in skin carotenoid status and blood carotenoid concentrations during controlled dietary intake ${ }^{(16)}$. This study was conducted according to the guidelines described in the Declaration of Helsinki, and all procedures involving human subjects and end point measurements were approved by the Institutional Review Board of the University of North Dakota. The parent study was powered solely to detect change in skin carotenoid status as measured by resonance Raman spectroscopy, and an $n 26$ was determined to provide $90 \%$ power to detect a $20 \%$ difference in skin carotenoid scores ${ }^{(16)}$. The present research represents a secondary outcome of that study.

Subjects were recruited via flyers, newspaper advertisements and word of mouth from the area of Grand Forks, ND, USA. The protocol was explained verbally and in writing by the investigators, and written informed consent was obtained from each volunteer. Baseline characteristics such as age, height, weight, BMI, body composition and blood chemistry are shown in Table 1. Subjects were apparently healthy women and men. Inclusion criteria were as follows: age $18-65$ years, a BMI $\left(\mathrm{kg} / \mathrm{m}^{2}\right)$ between 19 and 30 , weight stability of $\pm 2.7 \mathrm{~kg}$ within the past 2 months, willingness to refrain from smoking and the use of dietary supplements during the study period, willingness to maintain baseline weight and physical activity levels and willingness to complete study requirements, including consuming a provided diet. Subjects were excluded for gastrointestinal disorders, use of medications that could affect carotenoid metabolism, such as statins, current smoking, allergies or intolerances to foods used in the study or excessive alcohol use. Of the twentynine subjects who completed the study (Fig. 1), nine were male and twenty were female. Participants received a monetary stipend for completing the 28-week study.

\section{Dietary treatments}

The study consisted of four dietary treatment phases (Fig. 1). The first phase was a 6-week fruit and vegetable depletion phase (depletion-1) during which subjects were instructed to follow a low carotenoid diet (approximately $1 \mathrm{mg} / \mathrm{d}$ compared with the usual intake at the baseline, $12 \mathrm{mg} / \mathrm{d}$ ). The second phase was an 8-week high-fruit and vegetable controlled intervention phase during which the subjects consumed a provided experimental diet with approximately $60 \mathrm{mg}$ of total carotenoids per $\mathrm{d}$ from four to six cups of fruit and vegetables. Total carotenoids was defined as the sum of the six carotenoids ( $\alpha$-carotene, $\beta$-carotene, lycopene, $\beta$-cryptoxanthin, lutein/ zeaxanthin), which are predominant in the US diet and in the bloodstream. The details of the experimental diet can be found in Table 1 of the publication by Jahns et al. ${ }^{(16)}$. The third phase was the same as the first depletion phase (depletion-2) for 6 weeks. The fourth phase was an 8-week repletion phase (repletion) during which subjects were instructed to return to their usual diet as before entering the study.

Usual food intake was estimated from self-reported intakes by using the online version of the National Cancer Institute's Diet History Questionnaire (DHQ II*Web) ${ }^{(17-19)}$, which was developed based on previously validated DHQ I ${ }^{(20,21)}$. The subjects were asked to report their usual food intake over the past month at the baseline and the end of depletion-1, depletion-2 and repletion phases. The subjects were also required to complete 3 -d diet records after 1 week into depletion-1 and depletion-2, and during phase 4. The food records were then reviewed by a research dietitian and analysed with the US Department of Agriculture (USDA) National Nutrient Database for Standard Reference, release $23^{(1)}$, to ensure compliance with the dietary restrictions.

The experimental diet consisted of a $7-d$ rotating menu that was designed by registered dietitians and met the food-based recommendations of the Dietary Guidelines based on the example 2000-calorie food pattern menu ChooseMyPlate.gov ${ }^{(22)}$. The diet was designed to provide an average of six-cup equivalents of fruit and vegetables daily (fruit: $360-560 \mathrm{~g}$; vegetables: 450$705 \mathrm{~g}$ ). Fruit and vegetables were served cooked, raw and as $100 \%$ juice. All foods were weighed to the nearest tenth of a gram. Some examples of provided foods high in carotenoids include baked sweet potato, winter squash soup, vegetable juice, red grapefruit, spinach salad, broccoli, cantaloupe, carrots and red bell pepper, apricots, pumpkin custard and fruit juice, although this is not an exhaustive list. During the high fruit and vegetable experiment diet phase, all food and beverages were provided. Compliance with the intervention was assessed by a brief compliance questionnaire administered each weekday morning. Compliance with the depletion phases was measured with 3-d diet records to ensure that participants were indeed following a low-carotenoid prescription and understood the instructions. The subjects consumed breakfast at the Grand Forks Human Nutrition Research Center during the week and the remaining foods elsewhere. Subjects took home coolers containing all foods for the weekend. The consumption of non-energetic beverages was not controlled. The subjects were allowed to consume up to one or two alcoholic drinks per $\mathrm{d}$ for women or men, respectively. To maintain body weights during the provided diet phases, body weights were obtained each weekday and energy intakes were adjusted if the mean of weekly weights changed by $2 \%$.

Energy and macronutrient intakes for each treatment phase were estimated based on 3-d diet records, except the high-fruit and vegetable experimental diet, which was derived from the USDA Nutrient Database for Standard Reference Release $23^{(23)}$. Dietary potential renal acid load (PRAL) was calculated based on the following formula developed by Remer et al. ${ }^{(24)}$ as follows: PRAL $(\mathrm{mEq} / \mathrm{d})=(\mathrm{mg} \mathrm{P} / \mathrm{d} \times 0.0366)+(\mathrm{g}$ protein $/ \mathrm{d} \times 0.4888)-(\mathrm{mg}$ $\mathrm{K} / \mathrm{d} \times 0.0205)-(\mathrm{mg} \mathrm{Ca} / \mathrm{d} \times 0.0125)-(\mathrm{mg} \mathrm{Mg} / \mathrm{d} \times 0.0263)$.

\section{Blood chemistries, serum bone biomarkers and plasma carotenoid analyses}

Blood samples were drawn after an overnight fast at the baseline and at the mid-point and end points of each treatment phase and stored at $-80^{\circ} \mathrm{C}$ pending analysis. 
Serum alanine aminotransferase, aspartate aminotransferase, glucose, high-sensitivity C-reactive protein and a lipid profile were measured with Cobas 400 plus, and insulin was measured with Cobas e 411 (Roche Diagnostic). Quality control was performed according to the manufacturer's recommendation that is with a kit provided by the manufacturer each time before the assay and whenever a new cassette of reagent was put in use or a calibration was performed.

Serum samples at the end of each phase were analysed for bone formation and resorption biomarkers with commercial ELISA kits from Immunodiagnostic Systems: osteocalcin (kit no. AC-11F1), bone-specific alkaline phosphatase (BAP, kit no. AC-20), carboxyterminal cross-linking telopeptide (CTX, kit no. AC-02F1) and tartrate-resistant acid phosphatase (TRAP, kit no. SBTR201R), according to the manufacturers' instructions. Serum insulin-like growth factor 1 (IGF-1) was measured by using an ELISA kit (no. DG100) from R\&D Systems. The selection of these bone biomarkers was based on a few feeding trials with intake of fruit and vegetables ${ }^{(25-27)}$ and the consideration of limited available serum. Quality control of each bone biomarker was performed using two control samples in duplicate for each plate. The control samples with known concentrations (low value and high value) were supplied by respective kit manufacturers. The concentrations of the lowand high-value control samples must fall within the manufacturer's recommended range for the assay to be valid. The reference ranges for adults (male and female) are as follows: CTX, 25-1008 pg/ml; TRAP, 3.24 $\pm 0 \cdot 79-4 \cdot 36 \pm 0 \cdot 95$; BAP, 4.7$29 \cdot 3 \mu \mathrm{g} / \mathrm{l}$; IGF-1, 53-640 ng/ml; osteocalcin, 9-42 ng/ml.

Plasma carotenoids ( $\alpha$-carotene, $\beta$-carotene, $\beta$-cryptoxanthin, lycopene, lutein/zeaxanthin) were measured using HPLC with fluorescence detection based on the method with intra- and inter-day precision (between 0.95 and $5.31 \%$ and about $10 \%$, respectively) for all analytes conformed to Thurnham et al. ${ }^{(28)}$, as previously described ${ }^{(16)}$.

\section{Statistical analysis}

Data are reported as means with their standard errors. Effects of dietary treatment phases on blood variables were analysed by using repeated-measures ANOVA (JMP, version 9.0.0; SAS Institute, Inc.), where subject was a random effect. Normality was tested using Shapiro-Wilks test in JMP. Tukey contrasts were used for post hoc comparisons of the means. Pearson's correlation coefficients were calculated between plasma total and individual carotenoid and bone markers at baseline and the end of each dietary treatment. The method used ${ }^{(29)}$ provides estimates of both the within-individual correlation and the between-individual correlation across the course of the study, and correctly accounts for the multiple measurements on each subject.

\section{Results}

Of the thirty-eight individuals enrolled, twenty-nine completed the study and were included in data analysis (Fig. 1). The participants were general healthy, per experimental design, with a mean age of $32 \cdot 1$ (SEM 2.5) years and normal BMI (23.6

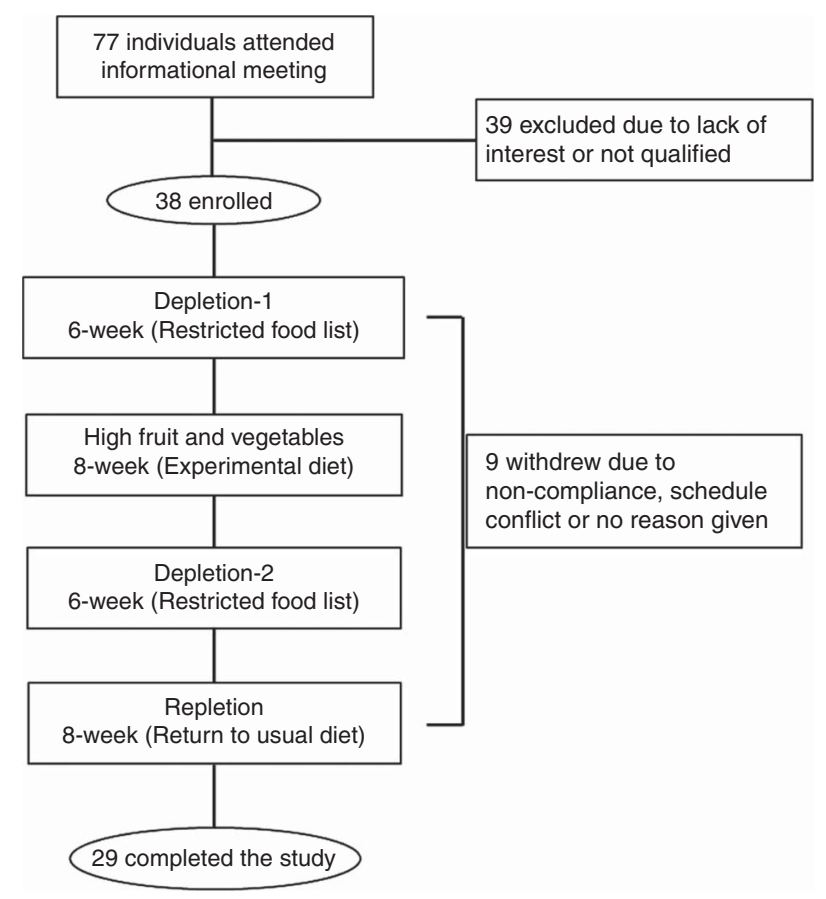

Fig. 1. Schematic of volunteer recruitment, experimental design and dietary treatments. In all, seventy-seven individuals attended information meeting and were screened for participation; twenty-nine completed the study.

(SEM 0.6$) \mathrm{kg} / \mathrm{m}^{2}$, and had a normal range of blood biochemistry profile when enrolled in the study (Table 1).

Compared with the baseline, decrements in fruit and vegetable intake (depletion-1) resulted in an increase in concentrations of serum total cholesterol and LDL-cholesterol (Table 1, $P<0.05$ ). High-fruit and vegetable diet decreased blood total cholesterol and HDL concentrations relative to the depletion- $1(P<0.05)$. Overall, dietary treatments had no effect on serum concentrations of alanine aminotransferase, aspartate aminotransferase, insulin, high-sensitivity C-reactive protein or TAG $(P>0.05)$.

Consistent with the study design, plasma carotenoid levels, a commonly used biomarker of fruit and vegetable intake, decreased as a result of the depletion phase and increased with the high-fruit and vegetable diet (Table 1).

Intake of nutrients of study participants was calculated on the basis of 3-d diet records based on the USDA National Nutrient Database for Standard Reference, release $23^{(23)}$. As expected, the participants in the high fruit and vegetable phase had the lowest calculated PRAL and relatively higher intakes of B vitamins than in depletion-1 and depletions-2 (Table 2).

The participants had lower concentrations of BAP (Fig. 2(A)), a bone formation marker, at the end of depletion-1 than at the baseline $(10.7$ (SEM 0.7) v. 9.5 (s and depletion-1, respectively, $P<0 \cdot 05$ ). Compared with the depletion-1 phase, elevated intake of fruit and vegetables increased serum BAP from 9.5 (SEM 0.8) to 11.3 (SEM 0.7) $\mu \mathrm{g} / \mathrm{l}$ $(P<0.05)$. Lower serum BAP concentrations were observed after the depletion-2 and repletion phases, compared with the highfruit and vegetable intake phase. There were no differences in other bone-formation-related markers, serum IGF-1 (Fig. 2(B)) and osteocalcin (Fig. 2(C)), among treatment phases $(P>0.05)$. 
Table 1. Characteristics and blood measurements of the study participants after an overnight fast ${ }^{\star}$ (Mean values with their standard errors; $n 29$ (nine male and twenty female))

\begin{tabular}{|c|c|c|c|c|c|c|c|c|c|c|}
\hline & \multicolumn{2}{|c|}{ Baseline } & \multicolumn{2}{|c|}{$\begin{array}{l}\text { Depletion-1 } \\
\text { (6 weeks) }\end{array}$} & \multicolumn{2}{|c|}{$\begin{array}{l}\text { High fruit and vegetable } \\
\text { (8 weeks) }\end{array}$} & \multicolumn{2}{|c|}{$\begin{array}{l}\text { Depletion-2 } \\
\text { (6 weeks) }\end{array}$} & \multicolumn{2}{|c|}{$\begin{array}{l}\text { Repletion } \\
\text { (8 weeks) }\end{array}$} \\
\hline & Mean & SEM & Mean & SEM & Mean & SEM & Mean & SEM & Mean & SEM \\
\hline Age (years) & $32 \cdot 1$ & $2 \cdot 5$ & & & & & & & & \\
\hline Weight (kg) & 69.5 & $2 \cdot 3$ & & & & & & & & \\
\hline BMI $\left(\mathrm{kg} / \mathrm{m}^{2}\right)$ & $23 \cdot 6$ & 0.6 & & & & & & & & \\
\hline Fat mass (kg) & $17 \cdot 0^{\mathrm{a}}$ & $1 \cdot 1$ & & & & & & & & \\
\hline Fat-free mass (kg) & $50 \cdot 8$ & $2 \cdot 2$ & & & & & & & & \\
\hline Fat percentage & $25 \cdot 3$ & 1.6 & & & & & & & & \\
\hline Alanine aminotransferase (nkat/l) & 318 & 52 & 330 & 35 & 342 & 42 & 302 & 37 & 342 & 30 \\
\hline Aspartate aminotransferase (nkat/l) & 347 & 32 & 316 & 22 & 328 & 15 & 301 & 14 & 338 & 19 \\
\hline Glucose $(\mathrm{mg} / \mathrm{dl}) \dagger$ & $89 \cdot 4^{a, b}$ & 1.6 & $90 \cdot 6^{\mathrm{a}}$ & $1 \cdot 1$ & $89 \cdot 4^{\mathrm{a}}$ & 1.5 & $85 \cdot 3^{\mathrm{b}}$ & 1.7 & $88 \cdot 1^{a, b}$ & $1 \cdot 2$ \\
\hline Insulin (pmol/l) & $55 \cdot 6$ & $13 \cdot 2$ & $41 \cdot 0$ & $6 \cdot 3$ & $36 \cdot 8$ & $5 \cdot 6$ & 38.9 & 6.9 & $59 \cdot 0$ & $11 \cdot 1$ \\
\hline High-sensitivity C-reactive protein (mg/l) & $2 \cdot 4$ & 0.6 & $2 \cdot 1$ & 0.7 & 2.9 & 1.0 & $1 \cdot 8$ & 0.6 & $2 \cdot 4$ & 0.7 \\
\hline Cholesterol $(\mathrm{mg} / \mathrm{dl}) \dagger$ & $167 \cdot 3^{\mathrm{b}}$ & $5 \cdot 4$ & $178 \cdot 1^{\mathrm{a}}$ & $7 \cdot 3$ & $165 \cdot 0^{\mathrm{b}}$ & $7 \cdot 6$ & $175 \cdot 7^{\mathrm{a}, \mathrm{b}}$ & 6.9 & $175 \cdot 1^{\mathrm{a}, \mathrm{b}}$ & $7 \cdot 7$ \\
\hline $\mathrm{HDL}(\mathrm{mg} / \mathrm{dl}) \dagger$ & $60 \cdot 3^{\mathrm{a}}$ & $2 \cdot 0$ & $61 \cdot 2^{\mathrm{a}}$ & $2 \cdot 8$ & $53.5^{\mathrm{b}}$ & $2 \cdot 3$ & $60 \cdot 2^{\mathrm{a}}$ & 1.9 & $61 \cdot 3^{a}$ & $2 \cdot 6$ \\
\hline LDL (mg/dl)† & $90 \cdot 5^{\mathrm{b}}$ & 4.8 & $100 \cdot 5^{a}$ & $6 \cdot 0$ & $95 \cdot 1^{a, b}$ & $6 \cdot 3$ & $99 \cdot 5^{a}$ & $6 \cdot 0$ & $96 \cdot 5^{a, b}$ & $6 \cdot 4$ \\
\hline TAG (mg/dl) $\dagger$ & $82 \cdot 8$ & $6 \cdot 7$ & 81.9 & $6 \cdot 1$ & 81.9 & $6 \cdot 7$ & $80 \cdot 3$ & $6 \cdot 3$ & $86 \cdot 6$ & 6.9 \\
\hline a-Carotene $(\mu \mathrm{mol} / \mathrm{l})$ & $0 \cdot 14^{\mathrm{c}, \mathrm{d}}$ & 0.02 & $0.11^{d}$ & 0.01 & $0.41^{a}$ & 0.02 & $0 \cdot 17^{\mathrm{b}, \mathrm{c}}$ & 0.01 & $0 \cdot 16^{c}$ & 0.01 \\
\hline$\beta$-Carotene $(\mu \mathrm{mol} / \mathrm{l})$ & $0.40^{\mathrm{b}, \mathrm{c}}$ & 0.05 & $0.30^{b, c}$ & 0.03 & $1.95^{\mathrm{a}}$ & 0.16 & $0.47^{\mathrm{b}}$ & 0.05 & $0.43^{b}$ & 0.04 \\
\hline$\beta$-Cryptoxanthin $(\mu \mathrm{mol} / \mathrm{l})$ & $0 \cdot 29^{b, c}$ & 0.05 & $0.16^{c, d}$ & 0.02 & $0.46^{\mathrm{a}}$ & 0.04 & $0.21^{d}$ & 0.02 & $0.29^{b}$ & 0.03 \\
\hline Lycopene $(\mu \mathrm{mol} / \mathrm{l})$ & $0.53^{b}$ & 0.05 & $0.27^{c}$ & 0.03 & $0.92^{\mathrm{a}}$ & 0.05 & $0.31^{c}$ & 0.03 & $0.54^{\mathrm{b}}$ & 0.04 \\
\hline Lutein/zeaxanthin $(\mu \mathrm{mol} / \mathrm{l})$ & $0.51^{b}$ & 0.05 & $0.36^{c}$ & 0.04 & $0.61^{a}$ & 0.04 & $0.40^{\mathrm{b}, \mathrm{c}}$ & 0.04 & $0.53^{b}$ & 0.04 \\
\hline Total carotenoids $(\mu \mathrm{mol} / \mathrm{l})$ & $1 \cdot 86^{\mathrm{b}, \mathrm{c}}$ & 0.14 & $1 \cdot 20^{\mathrm{d}}$ & 0.08 & $4 \cdot 35^{a}$ & 0.26 & $1.57^{\mathrm{C}}$ & 0.12 & $1.95^{\mathrm{b}}$ & 0.11 \\
\hline
\end{tabular}

a,b,c,d Mean values with unlike superscript letters were significantly different, $P<0.05$, among phases.

* Repeated-measures ANOVA where subject was a random effect was used to test for changes over phases of the study in blood parameters. Tukey contrasts were used for post hoc comparisons of means.

† To convert glucose in $\mathrm{mg} / \mathrm{dl}$ to $\mathrm{mmol} / \mathrm{l}$, multiply by 0.0555 ; to convert cholesterol, $\mathrm{HDL}$ and LDL in $\mathrm{mg} / \mathrm{dl}$ to $\mathrm{mmol} / \mathrm{l}$, multiply by 0.0259 ; to convert TAG in mg/dl to $\mathrm{mmol} /$, multiply by 0.0113 .

Table 2. Nutrient intakes of the study participants*

(Mean values with their standard errors)

\begin{tabular}{|c|c|c|c|c|c|c|c|c|c|c|}
\hline & \multicolumn{2}{|c|}{ Baseline† } & \multicolumn{2}{|c|}{ Depletion-1† (6 weeks) } & \multicolumn{2}{|c|}{ High fruit and vegetables $\ddagger$ ( 8 weeks) } & \multicolumn{2}{|c|}{ Depletion-2† (6 weeks) } & \multicolumn{2}{|c|}{ Repletion† (8 weeks) } \\
\hline & Mean & SEM & Mean & SEM & Mean & SEM & Mean & SEM & Mean & SEM \\
\hline Energy (kJ) & 9958 & 628 & 8803 & 389 & 8234 & 63 & 8887 & 506 & 8410 & 481 \\
\hline Energy (kcal) & 2380 & 150 & 2104 & 93 & 1968 & 15 & 2124 & 121 & 2010 & 115 \\
\hline Protein $(\mathrm{g})$ & 89.4 & $6 \cdot 1$ & 81.6 & $4 \cdot 1$ & $92 \cdot 0$ & 4.9 & $86 \cdot 1$ & 4.6 & $83 \cdot 2$ & 4.6 \\
\hline Carbohydrate (g) & 287 & 17 & 264 & 14 & 284 & 12 & 261 & $15 \cdot 4$ & 246 & $16 \cdot 2$ \\
\hline Fat $(g)$ & 95.9 & $8 \cdot 3$ & 80.5 & 4.5 & $56 \cdot 1$ & 3.9 & 83.3 & $6 \cdot 2$ & 77.6 & $5 \cdot 9$ \\
\hline Fibre (g) & $18 \cdot 8$ & 1.4 & $16 \cdot 0$ & $1 \cdot 1$ & $29 \cdot 2$ & $1 \cdot 7$ & $16 \cdot 4$ & 1.4 & $18 \cdot 4$ & $1 \cdot 2$ \\
\hline $\mathrm{Ca}(\mathrm{g})$ & 1174 & 134 & 1064 & 91 & 1914 & 139 & 1129 & 118 & 1199 & 129 \\
\hline $\mathrm{Cu}(\mathrm{mg})$ & 1.4 & 0.1 & 1.2 & 0.1 & 1.9 & 0.1 & 1.3 & 0.1 & 1.3 & 0.1 \\
\hline $\mathrm{Fe}(\mathrm{mg})$ & $17 \cdot 4$ & 1.6 & $16 \cdot 1$ & $1 \cdot 1$ & $20 \cdot 8$ & 2.9 & $17 \cdot 3$ & 1.4 & 17.5 & 1.6 \\
\hline $\mathrm{Mg}(\mathrm{mg})$ & 322 & 24 & 279 & $17 \cdot 6$ & 428 & 21 & 301 & $24 \cdot 7$ & 294 & $18 \cdot 4$ \\
\hline $\mathrm{Mn}(\mathrm{mg})$ & $3 \cdot 3$ & 0.3 & $3 \cdot 1$ & 0.3 & $4 \cdot 3$ & 0.4 & 3.4 & 0.3 & $3 \cdot 4$ & 0.3 \\
\hline$P(\mathrm{mg})$ & 1552 & 14 & 1417 & 27 & 1850 & 84 & 1483 & 80.9 & 1412 & 76 \\
\hline $\mathrm{Zn}(\mathrm{mg})$ & $12 \cdot 7$ & 0.7 & 11.5 & 0.6 & $16 \cdot 9$ & $2 \cdot 8$ & $12 \cdot 9$ & 0.8 & 13.9 & $1 \cdot 2$ \\
\hline $\mathrm{K}(\mathrm{mg})$ & 2824 & 206 & 2430 & 152 & 4485 & 279 & 2551 & 163 & 2705 & 180 \\
\hline $\mathrm{Na}(\mathrm{mg})$ & 3683 & 283 & 3094 & 157 & 3844 & 389 & 3152 & 225 & 3259 & 191 \\
\hline Vitamin A $(\mu \mathrm{g})$ & 760 & 72 & 517 & 44 & 2570 & 337 & 577 & 49 & 824 & 73 \\
\hline Vitamin D ( $\mu \mathrm{g})$ & 4.9 & $1 \cdot 1$ & $5 \cdot 6$ & 0.8 & $12 \cdot 0$ & 1.4 & $6 \cdot 1$ & 0.9 & $5 \cdot 7$ & 1.0 \\
\hline Vitamin $\mathrm{E}(a)(\mathrm{mg})$ & 9.5 & 1.9 & $5 \cdot 8$ & 0.4 & 24.4 & 3.0 & $7 \cdot 6$ & 1.7 & $8 \cdot 1$ & $1 \cdot 1$ \\
\hline Vitamin C (mg) & 100 & 18 & 58.4 & $12 \cdot 6$ & $245 \cdot 6$ & $35 \cdot 7$ & $47 \cdot 7$ & 7.4 & $97 \cdot 2$ & $16 \cdot 1$ \\
\hline Thiamin (mg) & $2 \cdot 0$ & 0.2 & 1.7 & 0.1 & 2.0 & 0.2 & 1.8 & 0.1 & 1.8 & 0.2 \\
\hline Riboflavin (mg) & $2 \cdot 7$ & 0.2 & $2 \cdot 3$ & 0.1 & 2.9 & 0.2 & 2.5 & 0.2 & 2.5 & 0.2 \\
\hline Niacin (mg) & $26 \cdot 9$ & 1.9 & $24 \cdot 6$ & $1 \cdot 3$ & 28.7 & 4.4 & $26 \cdot 7$ & $1 \cdot 8$ & $26 \cdot 8$ & $2 \cdot 1$ \\
\hline Vitamin $B_{6}(\mathrm{mg})$ & $2 \cdot 2$ & 0.2 & 1.9 & 0.1 & 3.3 & 0.4 & $2 \cdot 1$ & 0.2 & $2 \cdot 3$ & 0.2 \\
\hline Folate $(\mu \mathrm{g})$ & 505 & 46 & 403 & 26 & 771 & 125 & 432 & 31 & 486 & $45 \cdot 6$ \\
\hline Vitamin $B_{12}(\mu \mathrm{g})$ & $5 \cdot 7$ & 0.6 & $5 \cdot 2$ & 0.4 & 8.5 & 1.3 & $5 \cdot 8$ & 0.5 & $6 \cdot 1$ & 0.6 \\
\hline Total carotenoids $(\mathrm{mg}) \S$ & 11.5 & $1 \cdot 2$ & 1.4 & 0.2 & $62 \cdot 3$ & 0.9 & 1.5 & 0.4 & 9.0 & 1.0 \\
\hline PRAL (mEq)\| & 19.5 & 4.6 & 21.3 & $2 \cdot 8$ & $-16 \cdot 7$ & $5 \cdot 3$ & $22 \cdot 4$ & $2 \cdot 8$ & $14 \cdot 2$ & 3.5 \\
\hline
\end{tabular}

* Estimated based on the US Department of Agriculture National Nutrient Database for Standard Reference, release $23^{(23)}$

† On the basis of a 3-d diet record; $n 29$ (nine male and twenty female).

‡ Experimental diet; $n 7$ (calculated from 7-d rotating menu based on the US Department of Agriculture National Nutrient Database for Standard Reference, release $23^{(23)}$ ). $\S$ Calculated and reported ${ }^{(16)}$

II Calculated based on the formula developed by Remer et al. ${ }^{(24)}$ as PRAL $(\mathrm{mEq} / \mathrm{d})=(\mathrm{mg} \mathrm{P} / \mathrm{d} \times 0.0366)+(\mathrm{g} \mathrm{protein} / \mathrm{d} \times 0.4888)-(\mathrm{mg} \mathrm{K} / \mathrm{d} \times 0.0205)-(\mathrm{mg} \mathrm{Ca} / \mathrm{d} \times 0.0125)-(\mathrm{mg} \mathrm{Mg} /$ $d \times 0.0263)$. 
(A)

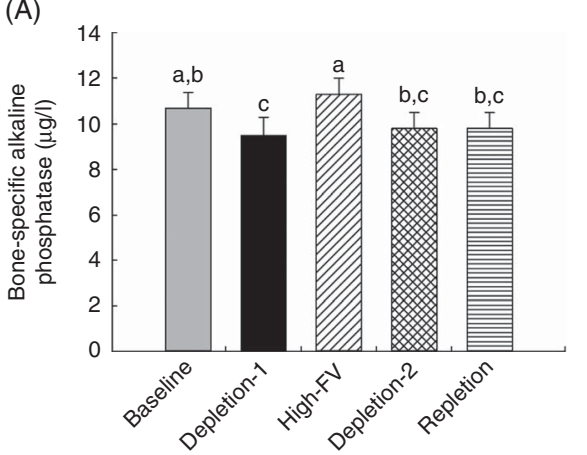

(B)

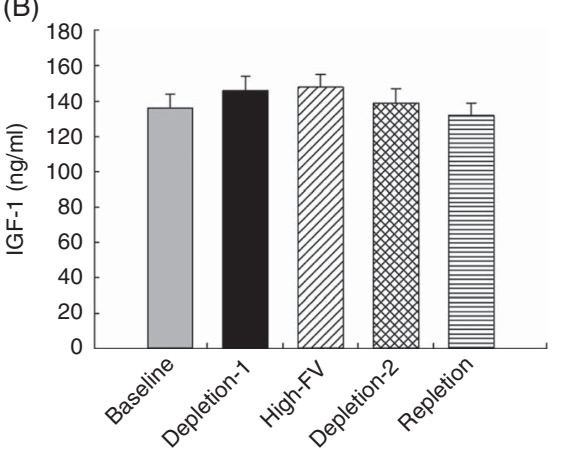

(C)

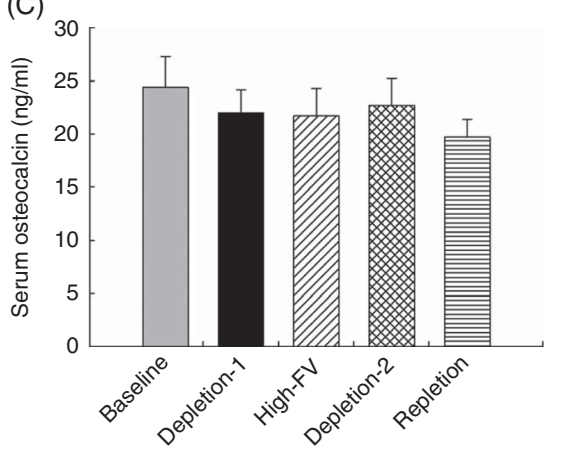

Fig. 2. Changes in serum bone formation markers in response to depletion and repletion of fruit and vegetables (FV). (a) Bone-specific alkaline phosphatase, (b) insulin-like growth factor 1 (IGF-1) and (c) osteocalcin. Values are means with their standard errors represented by vertical bars. Effects of dietary treatments on blood variables were analysed by using repeated-measures ANOVA (JMP, version 9.0.0; SAS Institute, Inc.), where subject was a random effect. Tukey contrasts were used for post hoc comparisons of means. ${ }^{a, b, c}$ Mean values with unlike superscript letters were significantly different $(P<0 \cdot 05)$.
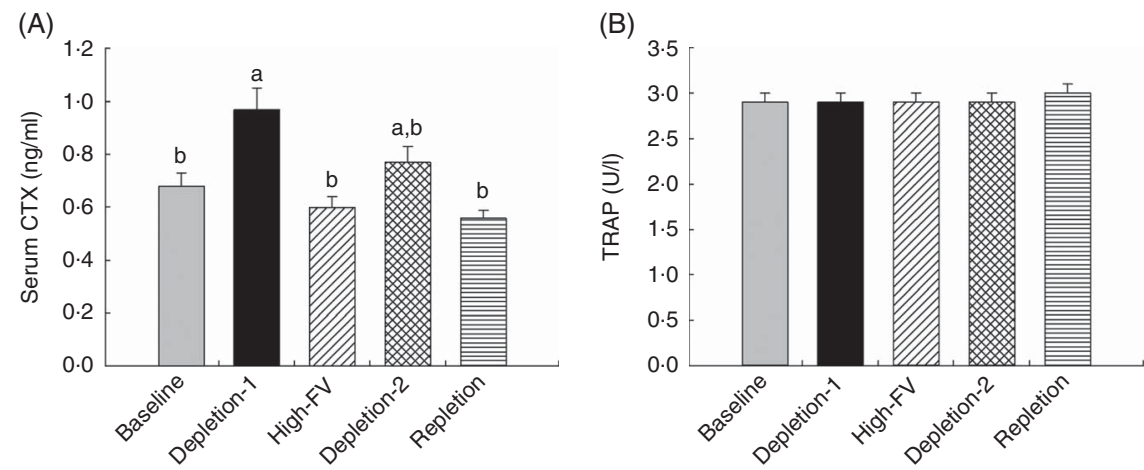

Fig. 3. Changes in serum bone resorption markers in response to depletion and repletion of fruit and vegetables. (a) Carboxyterminal cross-linking telopeptide (CTX), (b) tartrate-resistant acid phosphatase (TRAP). Values are means with their standard errors represented by vertical bars. Effects of dietary treatments on blood variables were analysed by using repeated-measures ANOVA (JMP, version 9.0.0; SAS Institute, Inc.), where subject was a random effect. Tukey contrasts were used for post hoc comparisons of means. ${ }^{a, b}$ Mean values with unlike superscript letters were significantly different $(P<0.05)$.

Compared with the baseline, concentrations of serum CTX (Fig. 3(A)), a bone resorption marker, were higher for the participants at the end of depletion-1 (0.68 (SEM 0.05) v. 0.97 (SEM $0.08) \mathrm{ng} / \mathrm{ml}$ for baseline and depletion-1, respectively, $P<0.05)$. High intake of fruit and vegetables decreased serum CTX to $0 \cdot 60($ SEM 0.04$) \mathrm{ng} / \mathrm{ml}$, compared with the depletion-1 $(P<0.05)$. Serum CTX concentrations were lower in repletion than depletion-1 $(P<0.05)$ and tended to be lower than depletion-2 $(P=0.051)$. Serum concentrations of TRAP were not affected by dietary treatment phases (Fig. 3(B), $P>0.05$ ).

Serum CTX concentrations were inversely correlated with blood lycopene $(r-0.39, P<0.05)$ and BAP concentrations were positively correlated with blood lycopene and $\beta$-cryptoxanthin ( $r \quad 0.43$ and $0.48, P<0.05$, respectively) within subjects. In addition, serum concentrations of BAP tended to positively correlate with blood total carotenoids and $\alpha$-carotene $(r 0.37$ and $0.34, P=0.06$ and 0.08 , respectively).

\section{Discussion}

In this secondary outcome analysis of a 28-week single-arm intervention feeding trial, we showed that concentration of serum CTX, a bone resorption marker, was increased while serum BAP, a bone formation marker, was decreased when the subjects were instructed to follow a prescribed diet low in carotenoids for 6 weeks. The concentration of CTX was decreased, whereas BAP was increased, when the subjects switched to a provided experimental diet high in fruit and vegetables (slightly above dietary guideline recommendations) for 8 weeks. Our data demonstrated that low intake of fruit and vegetables increases, whereas high intake decreases, bone turnover markers. To our knowledge, this is the first controlled intervention study to investigate depletion and repletion of fruit and vegetables on bone markers in healthy subjects. These findings strongly support that intake of fruit and vegetable at or above the amounts (five servings per $\mathrm{d}$ ) recommended by the 2015 Dietary Guidelines for Americans by the USDA Food Patterns $^{(1)}$ is beneficial to bone health.

With obesity growing in prevalence and an increased focus on diet modification to maintain healthy body weight and reduce obesity-related chronic disease, the influence of a high intake of fruit and vegetables on chronic diseases has attracted tremendous attention. High intake of fruit and vegetables as a component of a healthy diet pattern reduces obesity ${ }^{(7)}$ and is the only dietary characteristic being consistently recognised to be beneficial in almost every health outcome ${ }^{(1)}$. It is worth noting 
that in this study, relative to the baseline, depletion of fruit and vegetable intake (depletion-1) increased serum total cholesterol and LDL-cholesterol, whereas high intake lowered serum total cholesterol compared with the depletion-1 (Table 1); these findings are consistent with the well-established cardiovascular protective effect of fruit and vegetables ${ }^{(30)}$.

Available data from observational and prospective cohort studies support the beneficial effects of high fruit and vegetable intake on bone health. Greater intake of fruit and vegetables is positively associated with increased bone mineral density $^{(11,12,31,32)}$, decreased bone loss ${ }^{(33)}$ and reduced bone turnover ${ }^{(25,34)}$. Furthermore, high fruit and vegetable intake is inversely associated with the risk of bone fracture ${ }^{(14,25,35)}$, and Byberg et al. found that there was a dose-response inverse association between the intake of up to 5 servings/d of fruit and vegetables and hip fracture ${ }^{(9)}$. However, the lack of impact of increased fruit and vegetable consumption on bone turnover or bone mineral density has also been reported ${ }^{(34,36,37)}$. Data from controlled interventional studies regarding bone biomarkers in response to increased consumption of fruit and vegetables are lacking, and the findings from the few feeding trials are inconsistent $^{(26,27)}$

The fact that high intake of fruit and vegetables decreased serum CTX concentrations, whereas increased BAP concentrations, indicates reduced bone resorption and increased bone formation. These findings support results from the few uncontrolled intervention studies, which also showed a significant beneficial effect of increased consumption of fruit and vegetables on bone markers ${ }^{(25,27)}$. The Dietary Approaches to Stop Hypertension intervention study found that high fruit and vegetable consumption over a 30 -d period significantly decreased serum CTX by 16-18\% compared with a typical Western control diet in subjects aged $23-76$ years, similar to the age group in our study (aged 19-59 years) ${ }^{(27)}$. Similar findings from a double cross-over study reported ${ }^{(38)}$ that a diet low in fruit and vegetables resulted in a 19\% increase in CTX, although the study focused mainly on the acid content of the diet. Similarly, a 12-week intervention study by Gunn et al. ${ }^{(25)}$ reported that consuming nine servings of specific fruit and vegetables decreased serum CTX in postmenopausal women with osteopenia.

Our findings appear to be different with results from a 2-year intervention study in women aged 55-65 years that showed no significant effect of an additional $300 \mathrm{~g}$ of fruit and vegetables per $\mathrm{d}$ on bone turnover markers or bone mineral density ${ }^{(34)}$. However, in this study, the intake of fruit and vegetables was prescribed but not controlled, and the intake and compliance relied on a 3-d dietary checklist at each 3-month visit. A 16-week controlled intervention study by Neville et al. ${ }^{(26)}$ reported that increased fruit and vegetable consumption did not affect serum CTX or osteocalcin, a bone formation marker. This study, however, was conducted with subjects aged $65-85$ years who habitually consumed less than or equal to two servings of fruit and vegetables daily, and self-select their fruit and vegetables during the intervention phase. In contrast, the subjects in our study were 19-59 years of age with normal intake fruit and vegetables before they entered the study and given a provided diet. Compared with subjects with a normal dietary pattern who have been prescribed to consume less fruit and vegetables, it is possible that subjects who habitually consumed less fruit and vegetables would have a different physiological status and may respond differently to the same diet; for instance, carotenoid levels may be lower in those who are not vitamin A replete. In addition, older subjects might be less responsive to the similar dietary treatment than those younger subjects in our study.

Data regarding the effect of fruit and vegetables on bone formation markers are scarce and inconsistent. Changes of bone resorption markers have been the primary focus in many studies, as increased bone resorption relative to bone formation is the primary factor responsible for all forms of acquired osteoporosis $^{(39)}$. Increased serum BAP indicating increased bone formation, with intake of fruit and vegetables found in this study, has not been reported previously. In supporting our findings and consistent with the acid-base concept of fruit and vegetables, Ceglia et al. found that attenuating dietary acid load with the alkaline salt, potassium bicarbonate, increased serum IGF-1 levels $^{(40)}$, although no differences in serum IGF-1 levels among treatment phases have been detected in our study. However, Gunn et al. reported that increased intake of selected vegetables thought to be rich in phytochemicals that have bone resorption-inhibiting properties (such as citrus, cabbage and other cruciferous) decreased serum bone formation marker, procollagen type I N propeptide ${ }^{(25)}$, whereas Neville et al. reported that increased fruit and vegetable consumption had no effect on osteocalcin, also a bone formation marker.

The beneficial effects of fruit and vegetables on bone may be multifaceted, and several mechanisms have been suggested. A primary theory is the acid-base hypothesis in which an acidic environment would increase urinary $\mathrm{Ca}$ excretion and lead to bone resorption and bone $\operatorname{loss}^{(32,41,42)}$. Dietary acid load affecting $\mathrm{Ca}$ retention and bone health has been repeatedly demonstrated $^{(32,38)}$. In support of this hypothesis, several studies directly show that supplementing the base-forming mineral, potassium bicarbonate, decreased urinary Ca excretion and promoted $\mathrm{Ca}$ absorption ${ }^{(40,43-45)}$. PRAL, a measure of the acid-base load of foods, can be used to estimate renal net acid excretion $^{(24)}$. A lower PRAL indicates a higher content of fruit and vegetables that are rich in alkaline-forming components such as $\mathrm{K}, \mathrm{Ca}$ and $\mathrm{Mg}$. As expected, in this study, the provided diet high in fruit and vegetables had the lowest PRAL compared with diets in other experimental phases. Whether dietary acid load per se plays a primary role in the beneficial effects of high fruit and vegetable intake on bone has been disputed ${ }^{(46,47)}$, and the degree that the acid load of a diet affects $\mathrm{Ca}$ excretion and bone health has not been fully established. We previously showed that a diet high in acid load increases fractional dietary Ca absorption, which could partially compensate for increased urinary $\mathrm{Ca}$ excretion ${ }^{(48)}$.

Alternatively, nutrients that are abundant in fruit and vegetables, such as magnesium, potassium, $\alpha$-tocopherol, vitamin $\mathrm{K}$ and vitamin $\mathrm{C}$, might independently affect bone metabolism in addition to the acid-load properties ${ }^{(9,11)}$. Kang et al. ${ }^{(49)}$ reported that energetic intake, protein, carbohydrate, $\mathrm{Ca}, \mathrm{P}, \mathrm{Zn}$ and total food intake were negatively correlated with urinary deoxypyridinoline, a bone resorption marker. 
Last, fruit and vegetables contain phytochemicals with antioxidant properties such as flavonoids and carotenoids. It is well known that oxidative stress is detrimental ${ }^{(50)}$ and antioxidants are beneficial to bone ${ }^{(51)}$. Indeed, in this study we found that serum bone resorption marker, CTX, was inversely correlated with blood lycopene within subjects, whereas the bone formation marker BAP was positively correlated with blood lycopene and $\beta$-cryptoxanthin. These data suggest, therefore, that fruit and vegetables may affect bone indirectly via lower oxidative stress and inflammation by down-regulating osteoclastogenesis. The extent to which these potential mechanisms or others are acting with respect to fruit and vegetable intake needs further research.

This study has several strengths. First, the compliance with the intervention was ensured by provision of the entire diet, completion of 3 -d diet records after 1 week into each phase, use of a compliance questionnaire at each visit during the provided diet phase and exclusion of three non-compliant subjects from the study. Compliance was confirmed by the changes in blood and skin carotenoids, a characteristic of intake of fruit and vegetables, with each treatment phase ${ }^{(16)}$. Second, a unique feature of this study was that the same subjects were prescribed a low intake of fruit and vegetables and then switched to a provided diet high in fruit and vegetables, thus maximising the possibility of detecting an effect of increased consumption of fruit and vegetables. Third, the intake of six servings of fruit and vegetables in the provided diet phase was designed to be practical and consistent with the recommendation by the 2015 Dietary Guidelines for Americans ${ }^{(1)}$.

However, this study does possess limitations. Bone biomarker measurements were secondary end points, and the study was not specifically designed and powered for these end points. This may explain why we failed to observe changes in other bone markers in response to the intake of fruit and vegetables or detect significant differences in CTX ( $P=0.051)$ between depletion-2 phase and high intake of fruit and vegetables phase or between repletion and depletion- 2 phases. Changes in bone mineral density, an indicator positively correlated to fracture risk, in addition to bone markers would be useful, but a long-term study would be needed to detect such changes. As expected, we did not detect any changes in bone mineral density (data not shown) during the study given the short duration of each phase from 6 to 8 weeks. Other limitations were that adjustments for possible confounders, such as intake of $\mathrm{Ca}$, vitamin $\mathrm{D}$, gender, ethnicity or other lifestyle factors, were not made because our study was not powered to examine these outcomes.

In conclusion, data from this controlled depletion and repletion intervention study demonstrated positive effects of increasing consumption of fruit and vegetables on bone marker status in healthy adults. Although we cannot pinpoint specific contributions of particular fruit and vegetable components, these findings lend support to a whole-diet approach of increasing fruit and vegetable consumption to improve bone health.

\section{Acknowledgements}

The authors thank Clint Hall, Becky Stadstad, Craig Lacher and Brian Gregoire for their contributions to the study coordination and data collection. The authors thank Matthew Picklo for his critical review and suggestions to the manuscript.

Supported by the USDA Agricultural Research Service Current Research Information System nos 3062-51000-053-00D and 3062-51000-051-00D, as part of the authors' official duties.

The authors' responsibilities were as follows: J. J. C. contributed to the study design and implementation regarding bone-related end points, data analysis and interpretation and manuscript preparation; L. D. W. and L. J. contributed to the overall human clinic trial design and implementation, data interpretation and manuscript preparation or critical review of the manuscript.

The authors declare that there are no conflicts of interest.

\section{References}

1. US Department of Agriculture \& US Department of Health and Human Service (2015) Dietary Guidelines for Americans, 7th ed. Washington, DC: US Government Printing Office.

2. Oude Griep LM, Verschuren WM, Kromhout D, et al. (2011) Colours of fruit and vegetables and 10-year incidence of CHD. Br J Nutr 106, 1562-1569.

3. Wang X, Ouyang Y, Liu J, et al. (2014) Fruit and vegetable consumption and mortality from all causes, cardiovascular disease, and cancer: systematic review and dose-response meta-analysis of prospective cohort studies. BMJ 349, g4490.

4. Carter P, Gray LJ, Troughton J, et al. (2010) Fruit and vegetable intake and incidence of type 2 diabetes mellitus: systematic review and meta-analysis. BMJ 341, c4229.

5. Aune D, Chan DS, Vieira AR, et al. (2012) Fruits, vegetables and breast cancer risk: a systematic review and meta-analysis of prospective studies. Breast Cancer Res Treat 134, 479-493.

6. Lunet N, Lacerda-Vieira A \& Barros H (2005) Fruit and vegetables consumption and gastric cancer: a systematic review and meta-analysis of cohort studies. Nutr Cancer 53, 1-10.

7. Alinia S, Hels O \& Tetens I (2009) The potential association between fruit intake and body weight - a review. Obes Rev 10, 639-647.

8. Bellavia A, Larsson SC, Bottai M, et al. (2013) Fruit and vegetable consumption and all-cause mortality: a doseresponse analysis. Am J Clin Nutr 98, 454-459.

9. Byberg L, Bellavia A, Orsini N, et al. (2015) Fruit and vegetable intake and risk of hip fracture: a cohort study of Swedish men and women. J Bone Miner Res 30, 976-984.

10. Hamidi M, Boucher BA, Cheung AM, et al. (2011) Fruit and vegetable intake and bone health in women aged 45 years and over: a systematic review. Osteoporos Int 22, 1681-1693.

11. Chen YM, Ho SC \& Woo JL (2006) Greater fruit and vegetable intake is associated with increased bone mass among postmenopausal Chinese women. Br J Nutr 96, 745-751.

12. Prynne CJ, Mishra GD, O'Connell MA, et al. (2006) Fruit and vegetable intakes and bone mineral status: a cross sectional study in 5 age and sex cohorts. Am J Clin Nutr 83, 1420-1428.

13. Movassagh EZ, Kontulainen S, Baxter-Jones AD, et al. (2017) Are milk and alternatives and fruit and vegetable intakes during adolescence associated with cortical and trabecular bone structure, density, and strength in adulthood? Osteoporos Int 28, 609-619.

14. Benetou V, Orfanos P, Feskanich D, et al. (2016) Fruit and vegetable intake and hip fracture incidence in older men and women: the CHANCES project. I Bone Miner Res 31 , $1743-1752$. 
15. Feart C, Lorrain S, Ginder Coupez V, et al. (2013) Adherence to a Mediterranean diet and risk of fractures in French older persons. Osteoporos Int 24, 3031-3041.

16. Jahns L, Johnson LK, Mayne ST, et al. (2014) Skin and plasma carotenoid response to a provided intervention diet high in vegetables and fruit: uptake and depletion kinetics. Am J Clin Nutr 100, 930-937.

17. National Institutes of Health (2010) Diet*Calc Analysis Program, Version 1.5.0. Bethesda, MD: National Cancer Institute, Applied Research Program.

18. National Institutes of Health (2010) Questionnaire DH. Version 2.0. Bethesda, MD: National Cancer Institute, Applied Research Program.

19. National Institutes of Health (2010) DHQ Nutrient Database, dhq2.database.062510.csv. Bethesda, MD: National Cancer Institute, Applied Research Program.

20. Thompson FE, Subar AF, Brown CC, et al. (2002) Cognitive research enhances accuracy of food frequency questionnaire reports: results of an experimental validation study. J Am Diet Assoc 102, 212-225.

21. Subar AF, Thompson FE, Kipnis V, et al. (2001) Comparative validation of the Block, Willett, and National Cancer Institute food frequency questionnaires: the Eating at America's Table Study. Am J Epidemiol 154, 1089-1099.

22. US Department of Agriculture (2013) ChooseMyPlate. http:// www.choosemyplate.gov (accessed September 2017).

23. US Department of Agriculture \& Agricultural Research Service (2010) USDA national nutrient database for standard reference, release 23. http://www.ars.usda.gov/ba/bhnrc/ndl (accessed December 2013)

24. Remer T, Dimitriou T \& Manz F (2003) Dietary potential renal acid load and renal net acid excretion in healthy, free-living children and adolescents. Am J Clin Nutr 77, 1255-1260.

25. Gunn CA, Weber JL, McGill AT, et al. (2015) Increased intake of selected vegetables, herbs and fruit may reduce bone turnover in post-menopausal women. Nutrients 7, 2499-2517.

26. Neville CE, Young IS, Gilchrist SE, et al. (2014) Effect of increased fruit and vegetable consumption on bone turnover in older adults: a randomised controlled trial. Osteoporos Int 25, 223-233.

27. Lin PH, Ginty F, Appel LJ, et al. (2003) The DASH diet and sodium reduction improve markers of bone turnover and calcium metabolism in adults. J Nutr 133, 3130-3136.

28. Thurnham DI, Smith E \& Flora PS (1988) Concurrent liquidchromatographic assay of retinol, alpha-tocopherol, beta-carotene, alpha-carotene, lycopene, and beta-cryptoxanthin in plasma, with tocopherol acetate as internal standard. Clin Chem 34, 377-381.

29. Hamlett A, Ryan L, Serrano-Trespalacios P, et al. (2003) Mixed models for assessing correlation in the presence of replication. J Air Waste Manag Assoc 53, 442-450.

30. Boeing H, Bechthold A, Bub A, et al. (2012) Critical review: vegetables and fruit in the prevention of chronic diseases. Eur J Nutr 51, 637-663.

31. Liu ZM, Leung J, Wong SY, et al. (2015) Greater fruit intake was associated with better bone mineral status among Chinese elderly men and women: results of Hong Kong Mr. Os and Ms. Os studies. I Am Med Dir Assoc 16, 309-315.

32. Tucker KL, Hannan MT \& Kiel DP (2001) The acid-base hypothesis: diet and bone in the Framingham Osteoporosis Study. Eur J Nutr 40, 231-237.

33. Karamati M, Yousefian-Sanni M, Shariati-Bafghi SE, et al. (2014) Major nutrient patterns and bone mineral density among postmenopausal Iranian women. Calcif Tissue Int 94, 648-658.
34. Macdonald HM, Black AJ, Aucott L, et al. (2008) Effect of potassium citrate supplementation or increased fruit and vegetable intake on bone metabolism in healthy postmenopausal women: a randomized controlled trial. Am J Clin Nutr 88, 465-474.

35. Dai Z, Wang R, Ang LW, et al. (2014) Protective effects of dietary carotenoids on risk of hip fracture in men: the Singapore Chinese Health Study. J Bone Miner Res 29, 408-417.

36. McTiernan A, Wactawski-Wende J, Wu L, et al. (2009) Low-fat, increased fruit, vegetable, and grain dietary pattern, fractures, and bone mineral density: the Women's Health Initiative Dietary Modification Trial. Am J Clin Nutr 89, 1864-1876.

37. Nowson CA, Patchett A \& Wattanapenpaiboon N (2009) The effects of a low-sodium base-producing diet including red meat compared with a high-carbohydrate, low-fat diet on bone turnover markers in women aged 45-75 years. Br J Nutr 102, 1161-1170.

38. Buclin T, Cosma M, Appenzeller M, et al. (2001) Diet acids and alkalis influence calcium retention in bone. Osteoporos Int 12, 493-499.

39. Teitelbaum SL (2007) Osteoclasts: what do they do and how do they do it? Am J Pathol 170, 427-435.

40. Ceglia L, Harris SS, Abrams SA, et al. (2009) Potassium bicarbonate attenuates the urinary nitrogen excretion that accompanies an increase in dietary protein and may promote calcium absorption. J Clin Endocrinol Metab 94, 645-653.

41. New SA (2003) Intake of fruit and vegetables: implications for bone health. Proc Nutr Soc 62, 889-899.

42. Bushinsky DA (2001) Acid-base imbalance and the skeleton. Eur J Nutr 40, 238-244.

43. Sebastian A, Harris ST, Ottaway JH, et al. (1994) Improved mineral balance and skeletal metabolism in postmenopausal women treated with potassium bicarbonate. $N$ Engl J Med 330, 1776-1781.

44. Lemann J Jr, Gray RW \& Pleuss JA (1989) Potassium bicarbonate, but not sodium bicarbonate, reduces urinary calcium excretion and improves calcium balance in healthy men. Kidney Int 35, 688-695.

45. Dawson-Hughes B, Harris SS, Palermo NJ, et al. (2009) Treatment with potassium bicarbonate lowers calcium excretion and bone resorption in older men and women. $J$ Clin Endocrinol Metab 94, 96-102.

46. Fenton TR, Lyon AW, Eliasziw M, et al. (2009) Meta-analysis of the effect of the acid-ash hypothesis of osteoporosis on calcium balance. J Bone Miner Res 24, 1835-1840.

47. Hanley DA \& Whiting SJ (2013) Does a high dietary acid content cause bone loss, and can bone loss be prevented with an alkaline diet? J Clin Densitom 16, 420-425.

48. Cao JJ, Johnson LK \& Hunt JR (2011) A diet high in meat protein and potential renal acid load increases fractional calcium absorption and urinary calcium excretion without affecting markers of bone resorption or formation in postmenopausal women. J Nutr 141, 391-397.

49. Kang $\mathrm{MH}$, Kim MH, Bae YJ, et al. (2010) Vegetable and fruit intake and its relevance with serum osteocalcin and urinary deoxypyridinoline in Korean adults. Nutr Res Pract $\mathbf{4}$, 421-427.

50. Lean JM, Jagger CJ, Kirstein B, et al. (2005) Hydrogen peroxide is essential for estrogen-deficiency bone loss and osteoclast formation. Endocrinology 146, 728-735.

51. Cao JJ \& Picklo MJ (2014) N-acetylcysteine supplementation decreases osteoclast differentiation and increases bone mass in mice fed a high-fat diet. J Nutr 144, 289-296. 